\title{
Intragenomic sequence variations in the second internal transcribed spacer (ITS2) ribosomal DNA of the malaria vector Anopheles stephensi
}

\author{
Shobhna Mishra ${ }^{1}$, Gunjan Sharma ${ }^{1}$, Manoj K. Das ${ }^{2}$, Veena Pande $^{3}$, Om P. Singh $^{1}$, \\ ${ }^{1}$ National Institute of Malaria Research, Sector 8, Dwarka, New Delhi-110077, India \\ ${ }^{2}$ National Institute of Malaria Research, Field Unit, Itki, Ranchi-835301, India \\ ${ }^{3}$ Department of Biotechnology, Kumaun University, Nainital, Uttarakhand-263001, India \\ *Corresponding author \\ Email: dr.opsingh@gmail.com, singh@mrcindia.org (OPS)
}

\begin{abstract}
Second Internal Transcribed Spacer (ITS2) ribosomal DNA (rDNA) sequence is a widely used molecular marker for species-identification or -delimitation due to observed concerted evolution which is believed to homogenize rDNA copies in an interbreeding population. However, intra-specific differences in ITS2 of Anopheles stephensi have been reported. This study reports the presence of intragenomic sequence variation in the ITS2-rDNA of An. stephensi and hypothesizes that observed intra-specific differences in this species may have resulted due to ambiguous DNA sequencechromatogram resulting from intragenomic heterogeneity. Anopheles stephensi collected from different parts of India were sequenced for complete ITS2 and the variable region of 28S-rDNA (d1-d3 domains). Intragenomic variations were found in ITS2 region of all An. stephensi sequenced, but no such variation was observed in $\mathrm{d} 1$ to $\mathrm{d} 3$ domains of $28 \mathrm{~S}$-rDNA. Cloning and sequencing of ITS 2 through the $\mathrm{d} 3$ domain of the $28 \mathrm{~S}$ region of rDNA from representative samples from northern, central, and southern India confirmed the presence of intragenomic variation in ITS2 due to transitions at three loci and two bp indel in a di-nucleotide microsatellite locus. Multiple haplotypes were observed in ITS2 raised from such variations. Due to the absence of detectable intragenomic sequence variation in the d1 to $\mathrm{d} 3$ domain of $28 \mathrm{~S}$ rDNA of An. stephensi, this region can serve as an ideal reference sequence for taxonomic and phylogenetic studies. The presence of intragenomic variation in rDNA should be carefully examined before using this as a molecular marker for species delimitation or phylogenetic analyses.
\end{abstract}

Key words: Anopheles stephensi, intragenomic variation, ITS2, ribosomal DNA, malaria

\section{Introduction}

Anopheles stephensi is a major malaria vector in India, especially in an urban setting. This vector is predominantly found in urban areas due to their preference to breed in clean water especially in cement tanks, containers, overhead tanks, cisterns, fountain tanks, and building construction sites [1] which are abundant in urban areas. Perhaps due to its adaptation to such breeding habitats, this species has invaded several neighbouring territories. Because of the invasive nature of An. stephensi, coupled with the high 
infectivity rate to human-Plasmodium species [2-4], this malaria vector has now gained global health attention.

Historically, An. stephensi was recorded from the Middle-East and South Asia region (Afghanistan, Bahrain, Bangladesh, China, Egypt, India, Iran, Iraq, Oman, Pakistan, Saudi Arabia, Thailand) [1]. According to Sharma (2012) [5] An. stephensi is an invasive species that appeared first in the port cities in India and invaded the riparian town first and then the towns with excessive wells. During the last few decades, invasions of this species have been reported in Lakshadweep (India) [6], Sri Lanka [7-9], Republic of Djibouti [10], Ethiopia [11-12] and Sudan [13]. Anopheles stephensi is now established in the Horns of Africa and contributing to local malaria transmission [14-15]. As a consequence of reported invasions, Word Health Organization [13] alerted WHO-member-states and their implementing partners of affected countries to take immediate action.

Molecular markers, mainly the second internal transcribed spacer (ITS2) ribosomal DNA (rDNA) and cytochrome c oxidase, subunit 1 (COI) have been frequently used for the identification and confirmation of invasion of An. stephensi in several countries [7-8, 10-12, 15]. Another nuclear marker, intron of odorant-binding protein 1 (OBP1), has been reported to identify biological variants of $A n$. stephensi [16] and based on this marker, the presence of three sibling species in An. stephensi has been speculated [17]. Ribosomal DNA is the preferred and most widely used molecular marker for the delimitation of species and developing species-diagnostic assays being highly conserved in the interbreeding population due to the homogenization of copies which is thought to be achieved due to concerted evolution [24]. Ribosomal DNA is comprised of tandemly arranged units of ETS, 18S, ITS1, $5.8 \mathrm{~S}$, ITS2, and 28S, in several hundreds of copies in insects. DNA sequences of variable regions of 28S-rDNA, IGS and ITS2 in particular, have been frequently used for species identification, species delimitation, and phylogenetic analyses. 28S rDNA is a relatively conserved region, however, some domains ( $\mathrm{d} 2$ and $\mathrm{d} 3$ ) are variable and have been used as markers for species differentiation [18-23]. The second internal transcribed spacer region, on the other hand, which is relatively highly variable among different species because of its high evolution rate, is the most extensively used taxonomic marker for species identification and phylogenetic studies. However, in some species, intragenomic variations have been reported with the presence of multiple haplotypes. Such intragenomic variation poses a challenge in DNA sequencing especially when indel is present. The presence of indel leads to ambiguous sequencing result starting from the point of indel onwards which can be resolved through cloning [24]. The presence of such indels has resulted in the submission of incorrect sequences in GenBank or published reports. Such a phenomenon has recently been observed in the case of An. subpictus [25] and it was noted that all the reported intra-specific differences in a molecular form (Form A) of $A n$. subpictus was in fact due to ambiguous DNA sequence chromatogram resulting from the presence of indel in one of the two haplotypes of ITS2 present in each individual. The selection of the molecular region of rDNA, which can serve as reference sequences for the species identification, is therefore important and a region exhibiting intragenomic heterogeneity should be avoided. Moreover, recording of intragenomic sequence variation in rDNA becomes important while reporting sequence data to avoid ambiguities in taxonomic and phylogenetic studies.

In the case of An. stephensi, numerous ITS2 sequences are available in the GenBank and research publications [2, 8, 10, 26-28]. However, polymorphism in length and nucleotide sequence has been observed in sequences reported from Iran [26], India [28], and in several GenBank sequences. Such intraspecific polymorphism is intriguing. In some other reports from India [27], Saudi Arabia [29], Ethiopia [11] and Sri Lanka [8], however, no intraspecific differences were noted. One plausible reason, 
which explains reporting of polymorphism, is the presence of intragenomic sequence variation which has not been taken care of during DNA sequence analysis.

In this study, we characterized partial 5.8S, complete ITS2, and partial $28 \mathrm{~S}$ (d1 to $\mathrm{d} 3 \mathrm{domains}$ ) of An. stephensi to investigate intragenomic variations and delineate the region of rDNA suitable for molecular taxonomy that can be correctly sequenced without the need for cloning.

\section{Material and methods}

\section{Mosquito samples}

Anopheles stephensi mosquitoes were collected from different parts of India, i.e., Gurugram (Haryana), Nuh (Haryana), Alwar (Rajasthan), and New Delhi from northern India, Ranchi (Jharkhand), Raipur (Chattishgarh), and Gadhchiroli (Maharashtra) from central India, Goa, Bangalore (Karnataka) Mangalore (Karnataka), Chennai (Tamil Nadu) and Mysuru (Karnataka) from southern India (Figure 1). The geographical coordinates of collection sites have been provided in Table 1. Individual mosquitoes were preserved in a microfuge tube containing a piece of dehydrated silica gel and transported to the laboratory at Delhi. Mosquitoes were identified using keys by Christophers [31] before DNA isolation.

\section{DNA isolation and direct sequencing}

DNA was isolated from individual female mosquitoes using the method by Livak [30]. A part of rDNA spanning part of 5.8S rDNA, complete ITS2, and part of 28S rDNA (d1 to d3 domains) was amplified by using primers ITS2A (5'-TGT GAA CTG CAG GAC ACA T-3') [32] and D3B (5'-TCG GAA GGA ACC AGT TAC TA-3') [33]. The PCR reaction mixture $(20 \mu \mathrm{L})$ contained $1 \mathrm{X}$ buffer, $1.5 \mathrm{mM} \mathrm{MgCl}$, $200 \mu \mathrm{M}$ of each dNTP, $0.25 \mu \mathrm{M}$ of each primer, 0.50 unit of Taq polymerase (GoTaq ${ }^{\circledR}$, Promega Corporation Inc), and $0.5 \mu \mathrm{L}$ of DNA template. The PCR conditions were: an initial denaturation step at $95^{\circ} \mathrm{C}$ for $3 \mathrm{~min}$, followed by 35 cycles each with a denaturation step at $95{ }^{\circ} \mathrm{C}$ for $30 \mathrm{sec}$, annealing step at $55^{\circ} \mathrm{C}$ for $30 \mathrm{sec}$ and extension step at $72{ }^{\circ} \mathrm{C}$ for $1.5 \mathrm{~min}$, followed by a final extension at $72{ }^{\circ} \mathrm{C}$ for 7 min. The quality of PCR product was checked on $1.5 \%$ agarose gel under UV gel documentation unit. The PCR products were subjected to DNA sequencing using Sanger's method. The PCR products were treated with Exo-Sap (ExoSAP-IT ${ }^{\mathrm{TM}}$, Thermo Fisher, USA) to remove unutilized primers and dNTPs, and subjected to cycle sequencing reaction using BigDye Terminator v3.2 (Invitrogen Inc., USA) following vendor's protocol. The primers used for sequencing termination reaction were ITS2A, ITS2D (5'-TAT GCT TAA ATT CTG AGG GT-3'), D2A (5'-AGT CGT GTT GCT TGA TAG TGC AG-3') [34], D2B (5'-TTG GTC CGT GTT TCA AGA CGG G-3') [34], D3A (5'-GAC CCG TCT TGA AAC ACG GA-3') [33] and D3B. The sequence termination reaction products were cleaned up using ethanol precipitation and were electrophoresed in ABI Prism 3730xl. The numbers of samples sequenced from different parts of India has been shown in Table 1.

\section{Cloning and sequencing}

For cloning, the rDNA spanning partial 5.8S, ITS2 and partial 28S was first amplified from six individual female mosquitoes, two each from Nuh (representing northern India), Gadchiroli (central India) and Chennai (representing southern India) using a high-fidelity DNA Taq polymerase to minimize PCR-errors. The PCR reaction mixture $(25 \mu \mathrm{L})$ contained $0.5 \mu \mathrm{M}$ of each forward and reverse primer (ITS2A and D3B), 0.50 unit of Phusion ${ }^{\circledR}$ High-Fidelity DNA Polymerase, $5 \mu \mathrm{L}$ of $5 \mathrm{X}$ Phusion HF reaction buffer (all from New England Biolabs, USA), $0.5 \mu \mathrm{L}$ of $10 \mathrm{mM}$ premixed dNTPs and 0.5 
$\mu \mathrm{L}$ of gDNA. PCR conditions were: initial denaturation at $98^{\circ} \mathrm{C}$ for $30 \mathrm{sec}, 35$ cycles of each of denaturation at $98^{\circ} \mathrm{C}$ for $10 \mathrm{sec}$, annealing at $65^{\circ} \mathrm{C}$ for $30 \mathrm{sec}$ and extension at $72{ }^{\circ} \mathrm{C}$ for $45 \mathrm{sec}$, followed by a cycle of final extension at $72{ }^{\circ} \mathrm{C}$ for $2 \mathrm{~min}$. Five $\mu \mathrm{L}$ of PCR products were visualized on $1.5 \%$ agarose gel and the remaining were purified using QIAquick PCR purification kit (Qiagen Inc, USA) following the manufacturer's protocol. A-tail was incorporated at 3' end of the purified PCR product by incubating $50 \mathrm{ng}$ of PCR product at $70^{\circ} \mathrm{C}$ for $20 \mathrm{~min}$ in a reaction mixture $(20 \mu \mathrm{L})$ containing 1X PCR buffer, $1.5 \mathrm{mM} \mathrm{MgCl} 2,0.5$ unit of Taq DNA polymerase, and $200 \mu \mathrm{M}$ of dATP. Four $\mu \mathrm{L}$ of purified A-tailed PCR products were ligated to pGEM-T easy vector (Promega Corporation) and $5 \mu \mathrm{L}$ of this ligated mixture was then transformed into DH5 $\alpha$ competent cells (New England Biolab, USA). Transformed cultures were plated on Luria-Bertani (LB) agar plates containing 5-bromo-4chloro-3-indolyl-beta-D-galactopyranoside (X-gal), isopropyl-beta-D-thiogalactopyranoside (IPTG), and $50 \mu \mathrm{g} / \mathrm{mL}$ ampicillin. White transformant colonies originating from each mosquito were picked up and DNA was isolated by boiling them in TE buffer at $95^{\circ} \mathrm{C}$. The plasmid DNA was subjected to PCR using primers ITS2 and D3B and the amplified products with successful insert, as evident from the size of PCR product on agarose gel, were treated with Exo-Sap. Sequencing of plasmid DNA was performed using primers ITS2A, ITS2D, D2A D2B, D3A and D3B.

\section{Results}

Sequencing of cloned PCR products revealed the presence of a total of ten haplotypes. The sequences of all haplotypes are available at GenBank (accession numbers MW676288-MW676295, MW732930MW732931). Since NCBI no more accept annotation of rDNA sequences submitted, due to a recent policy change, annotation details have been provided in supplementary file S1. Polymorphism in nucleotide sequences were restricted to ITS2 region only and no polymorphism was recorded in flanking $5.8 \mathrm{~S}$ and $\mathrm{d} 1$ to $\mathrm{d} 3$ domains of $28 \mathrm{~S}$. The alignment of ITS2 sequences in respect to all haplotypes have been shown in Figure 2. All the haplotypes resulted due to SNPs at three fixed loci in the ITS2 region, i.e., C>T transition at nucleotide base positions 172 and 383, G>A transition at 401, and two bp indel (CA) at base positions 182-183 (base position numbering as per Figure 2). To avoid inclusion of an SNP in cloned samples resulting from possible PCR error, any SNP which was present only in one clone, were suspected to be raised from PCR error and were excluded from the analysis. The number of clones sequenced and distribution of haplotypes in representative samples from three populations have been shown in Table 2. The Hap-1 was the dominant haplotype.

Direct sequencing of An. stephensi from different localities, representing northern, central, and southern India, was also performed for ITS2 and d1-d3 domains of 28S-rDNA (Table 1). Due to the presence of indel at base positions 182-183 of ITS2, all sequences were ambiguous in sequence reads beyond this point (Figure 3). Therefore, forward sequences were read before the indel point and reverse sequences were read after the indel. Mixed bases were seen at all polymorphic loci, as seen in clonal sequencing, in all the samples. However, it was difficult to recognize transition $383 \mathrm{C}>\mathrm{T}$ in some samples and differentiate it from the noise due to the low peak area of T-allele. The result shows that intragenomic variation is universal, at least in the Indian population. The direct sequence chromatogram also showed that CA-microsatellite present in ITS2 (base positions 172-182) was dimorphic (with six or seven repeats) and not highly polymorphic like other microsatellites. No polymorphism was seen in the coding rDNA (5.8S and d1 to d3 domains of $28 \mathrm{~S})$.

To investigate if mixed haplotypes in An. stephensi is due to the hybridization of type form and var. mysorensis, two individuals of each form were also sequenced for ITS2 and 28S rDNA. No difference was found in the sequence and pattern of intragenomic variations. 


\section{Discussion}

Ribosomal DNA sequence is a widely used molecular taxonomic marker for speciesidentification/delimitation and phylogenetic studies due to homogenization of copies of rDNA in an interbreeding population through observed concerted evolution, which leads to a remarkably low or complete absence of intra-specific variation. Among rDNA regions, the ITS2-rDNA is the most frequently used molecular marker that exhibits remarkably high inter-specific differentiation due to high evolution rate, although it remains under evolutionary constraints to maintain the specific secondary structures that provide functionality [35] of rDNA. However, the use of rDNA in molecular systematics and phylogenetic studies sometimes becomes problematic due to intragenomic variation, particularly indel. Intragenomic variations in rDNA, particularly in noncoding rDNA (ITS2 and IGS), are not uncommon and have been observed in several organisms including anophelines [36-40]. The indel in some copies of rDNA sequence significantly affects the DNA sequence quality which leads to the collapse of the DNA sequence chromatogram [24] downstream to the point of indel. Instances exist where such intragenomic variations are overlooked and potentially inaccurate sequences are submitted to GenBank or documented in the research articles. A recent report by Sindhania et al. [25] revealed that most of the ITS2-sequences of a molecular form of An. subpictus (prevalent mainly in Indian mainland, Form A) available in the public domain are incorrect due to the presence of indel in one haplotype that was unnoticed by the investigators. Therefore, the generation of quality sequence and documentation of the presence of intragenomic variation in rDNA is essential for the correct molecular characterization of a species.

The ITS2 sequences of An. stephensi have been reported by several authors but intragenomic variations remained unnoticed. However, significant intra-specific variations in ITS2 have been reported. It is suspected that the observed intraspecific polymorphism in ITS2 is raised due to compromised sequence quality. Such intraspecific variations have been exploited for population genetic analysis [26] which may be misleading. In a study carried out in Sri Lanka [8], only a part of sequences, representing approximately half of the sequence generated (using primers from $5.8 \mathrm{~S}$ and $28 \mathrm{~S}$ rDNA), were submitted. Similarly, partial sequences were submitted from the Horn of Africa [2]. Trimming of significant portions of DNA sequence in these studies is probably due to ambiguities encountered in sequence read due to intragenomic variation particularly indel at the microsatellite locus. However, none of the reports documented intragenomic variation except in one GenBank entry from the Horn of Africa [2] (accession number: MN826065) where mixed bases (G/A) have been shown at base position 401. It is most likely that intragenomic variation is present beyond India which is evident from the fact that the sequences available from the public domain from other countries are either divergent or only fragments of the sequences have been reported. However, the presence of intragenomic variation in other countries needs confirmation. This study also revealed that polymorphic sites are fixed in all Indian populations studied. A similar observation has been documented in the case of An. subpictus (molecular Form A) where two ITS2 haplotypes were found present in all populations from northern India to Sri Lanka [25].

The presence of intragenomic sequence variation in An. stephensi is indicative of less efficient concerted evolution acting on rDNA which can be due to the presence of multiple clusters of rDNA in the genome. Although the exact mechanisms of observed concerted evolution remain unclear, the homogenization of rDNA is believed to be due to a variety of genomic mechanisms of turnover such as unequal crossing over and gene conversion [41]. However, the concerted evolution is predicted to act less efficiently upon dispersed rDNA units [42] due to less frequent recombination on heterologous chromosomes [43]. Localization of rDNA clusters in An. stephensi through fluorescent in-situ 
hybridization (FISH) have revealed the presence of rDNA on both X and Y chromosomes [44], similar to Drosophila melanogaster [45] where interchromosomal exchanges are likely to be less efficient to homogenize rDNA. We noted intragenomic variations in ITS2 (non-coding rDNA) only but no evidence of intragenomic variation was found in coding rDNA sequenced in this study (partial 5.8S and d1-d3 domains of 28S-rDNA). Several reports cited by Keller et al. (2006) [46] have shown that often such intragenomic variation is restricted to the noncoding rDNA regions.

Due to limited numbers of clones sequenced, the possibility of missing some rare variants, if any, may exist; although, such variations, if present in very low frequency, will not be affecting the quality of direct sequencing chromatogram and utility of sequence in species delimitation or phylogenetic studies. It has been shown [47] that DNA copies that are present in less than one-tenth proportion do not have obvious signals in sequence chromatogram. All the variations we observed through clonal sequencing in An. stephensi can be seen in a direct-sequencing chromatogram. Thus intragenomic variations can also be detected to a greater extent through careful examination of direct sequencing chromatograms through the eye without the need for cloning. However, the quality of DNA sequence with minimal noise at the base of chromatogram is crucial. The noise in the DNA sequence can be significantly reduced by choosing a sequencing primer different than the primers that were used for PCR amplification. This eliminates parallel sequencing of PCR artifacts such as non-specific PCR products present in very low quantity and primer-dimers.

The second internal transcribed spacer region has been an extensively used molecular marker for species characterization, however, coding regions of rDNA have also been used for this purpose. The 28S-rDNA, which is believed to be highly conserved, has less frequently been used in molecular taxonomy. However, the variable regions of 28S-rDNA, i.e., D2 and D3 domain [18-23] have exhibited the taxonomic significance and have been used for developing molecular differentiation of closely related sibling species/groups. This study provides the first-ever reference sequence of An. stephensi for $\mathrm{d} 1$ to $\mathrm{d} 3$ domains of $28 \mathrm{~S}$ rDNA. This region didn't exhibit obvious intragenomic sequence variation. Therefore, this sequence can be used as a reference sequence for An. stephensi for molecular taxonomy.

\section{Conclusions}

Due to the presence of intragenomic sequence variations in the ITS2-rDNA of An. stephensi, this region is not a suitable molecular marker for the identification of An. stephensi and molecular phylogenetic analysis. The 28S-rDNA (d1 through d3 domains) sequence can serve as a superior molecular marker for this purpose due to the absence of intragenomic variation.

\section{Acknowledgements}

The authors are thankful to Dr. Robin Marwal for providing specimens of type form and var mysorensis, Dr. V.P. Ojha for providing mosquitoes from Gadchiroli, Mr. Shri Bhagwan for collecting mosquitoes from Chennai and Mr Uday Praksh and Mr NS Bhakuni for technical support.

\section{References}

1. Dash AP, Adak T, Raghavendra K, Singh OP. The biology and control of malaria vectors in India. 2007; Curr Sci: 92, 1571-1578. 
2. Tadesse FG, Ashine T, Teka H, Esayas E, Messenger LA, Chali W, et al. Anopheles stephensi mosquitoes as vectors of Plasmodium vivax and falciparum, Horn of Africa, 2019. Emerg Infect Dis. 2021; 27:603-607. doi: 10.3201/eid2702.200019.

3. Adak T, Kaur S, Singh OP. Comparative susceptibility of different members of the Anopheles culicifacies complex to Plasmodium vivax. Trans R Soc Trop Med Hyg. 1999; 93:573-7. doi: 10.1016/s0035-9203(99)90052-4.

4. Kaur S, Singh OP, Adak T. Susceptibility of species A, B, and C of Anopheles culicifacies complex to Plasmodium yoelii yoelii and Plasmodium vinckei petteri infections. J Parasitol. 2000; 86:1345-8. doi: 10.1645/0022-3395(2000)086[1345:SOSABA]2.0.CO;2.

5. Sharma VP. Continuing challenge of malaria in India. 2012; Curr Sci, 102: 678-682

6. Sharma SK, Hamzakoya KK. Geographical spread of Anopheles stephensi vector of urban Malaria, and Aedes aegypti, vector of dengue/ DHF, in the Arabian Sea Islands of Lakshadweep, India. Dengue Bulletin. 2001; 25: 88-91. https://apps.who.int/iris/handle/10665/148798

7. Gayan Dharmasiri AG, Perera AY, Harishchandra J, Herath H, Aravindan K, Jayasooriya HTR, et al. First record of Anopheles stephensi in Sri Lanka: a potential challenge for prevention of malaria reintroduction. Malar J. 2017; 16:326. doi: 10.1186/s12936-017-1977-7.

8. Surendran SN, Sivabalakrishnan K, Gajapathy K, Arthiyan S, Jayadas TTP, Karvannan K, et al. Genotype and biotype of invasive Anopheles stephensi in Mannar Island of Sri Lanka. Parasit Vectors. 2018; 11:3. doi: 10.1186/s13071-017-2601-y.

9. Surendran SN, Sivabalakrishnan K, Sivasingham A, Jayadas TTP, Karvannan K, Santhirasegaram S, et al. Anthropogenic factors driving recent range expansion of the malaria vector Anopheles stephensi. Front Public Health. 2019; 7:53. doi: 10.3389/fpubh.2019.00053.

10. Faulde MK, Rueda LM, Khaireh BA. First record of the Asian malaria vector Anopheles stephensi and its possible role in the resurgence of malaria in Djibouti, Horn of Africa. Acta Trop. 2014; 139:39-43. doi: 10.1016/j.actatropica.2014.06.016.

11. Carter TE, Yared S, Gebresilassie A, Bonnell V, Damodaran L, Lopez K, et al. First detection of Anopheles stephensi Liston, 1901 (Diptera: culicidae) in Ethiopia using molecular and morphological approaches. Acta Trop. 2018; 188:180-186. doi:

10.1016/j.actatropica.2018.09.001.

12. Balkew M, Mumba P, Dengela D, Yohannes G, Getachew D, Yared S, et al. Geographical distribution of Anopheles stephensi in eastern Ethiopia. Parasit Vectors. 2020; 13:35. doi: 10.1186/s13071-020-3904-y..

13. WHO. Vector alert: Anopheles stephensi invasion and spread. 26 August 2019. https://www.who.int/news/item/26-08-2019-vector-alert-anopheles-stephensi-invasion-andspread (retrieved: 1 March, 2021)

14. Seyfarth M, Khaireh BA, Abdi AA, Bouh SM, Faulde MK. Five years following first detection of Anopheles stephensi (Diptera: Culicidae) in Djibouti, Horn of Africa: populations establishedmalaria emerging. Parasitol Res. 2019; 118:725-732. doi: 10.1007/s00436-019-06213-0.

15. de Santi VP, Khaireh BA, Chiniard T, Pradines B, Taudon N, Larréché S, Mohamed AB, de Laval F, Berger F, Gala F, Mokrane M, Benoit N, Malan L, Abdi AA, Briolant S. Role of Anopheles stephensi Mosquitoes in Malaria Outbreak, Djibouti, 2019. Emerg Infect Dis. 2021; 27:1697-1700. doi: 10.3201/eid2706.204557.

16. Gholizadeh S, Firooziyan S, Ladonni H, Hajipirloo HM, Djadid ND, Hosseini A, Raz A. The Anopheles stephensi odorant binding protein 1 (AsteObp1) gene: a new molecular marker for biological forms diagnosis. Acta Trop. 2015; 146:101-13. doi:

10.1016/j.actatropica.2015.03.012. 
17. Firooziyan S, Dinparast Djadid N, Gholizadeh S. Speculation on the possibility for introducing Anopheles stephensi as a species complex: preliminary evidence based on odorant binding protein 1 intron I sequence. Malar J. 2018; 17:366. doi: 10.1186/s12936-018-2523-y

18. Sharpe RG, Hims MM, Harbach RE, Butlin RK. PCR-based methods for identification of species of the Anopheles minimus group: allele-specific amplification and single-strand conformation polymorphism. Med Vet Entomol. 1999; 13:265-73. doi: 10.1046/j.13652915.1999.00178.x.

19. Singh OP, Chandra D, Nanda N, Raghavendra K, Sunil S, Sharma SK, et al. Differentiation of members of the Anopheles fluviatilis species complex by an allele-specific polymerase chain reaction based on 28S ribosomal DNA sequences. Am J Trop Med Hyg. 2004; 70:27-32.

20. Singh OP, Goswami G, Nanda N, Raghavendra K, Chandra D, Subbarao SK. An allele-specific polymerase chain reaction assay for the differentiation of members of the Anopheles culicifacies complex. J Biosci. 2004; 29:275-80. doi: 10.1007/BF02702609.

21. Alam MT, Das MK, Dev V, Ansari MA, Sharma YD. PCR-RFLP method for the identification of four members of the Anopheles annularis group of mosquitoes (Diptera: Culicidae). Trans $\mathrm{R}$ Soc Trop Med Hyg. 2007; 101:239-44. doi: 10.1016/j.trstmh.2006.03.007.

22. Singh OP, Nanda N, Chandra D, Jha D, Adak T, Dua VK, et al. Modified PCR-based assay for the differentiation of members of Anopheles fluviatilis complex in consequence of the discovery of a new cryptic species (species V). Malar J. 2020; 19:96. doi: 10.1186/s12936-020-03172-1.

23. Raghavendra K, Cornele AJ, Reddy BP, Collins FH, Nanda N, Chandra D, et al. Multiplex PCR assay and phylogenetic analysis of sequences derived from D2 domain of 28S rDNA distinguished members of the Anopheles culicifacies complex into two groups, A/D and B/C/E. Infect Genet Evol. 2009; 9:271-7. doi: 10.1016/j.meegid.2008.12.007.

24. Beebe NW. DNA barcoding mosquitoes: advice for potential prospectors. Parasitology. 2018; 145:622-633. doi: 10.1017/S0031182018000343.

25. Sindhania A, Das MK, Sharma G, Surendran SN, Kaushal BR, Lohani HP, et al. Molecular forms of Anopheles subpictus and Anopheles sundaicus in the Indian subcontinent. Malar J. 2020; 19:417. doi: 10.1186/s12936-020-03492-2.

26. Djadid ND, Gholizadeh S, Aghajari M, Zehi AH, Raeisi A, Zakeri S. Genetic analysis of rDNAITS2 and RAPD loci in field populations of the malaria vector, Anopheles stephensi (Diptera: Culicidae): implications for the control program in Iran. Acta Trop. 2006; 97:65-74. doi: 10.1016/j.actatropica.2005.08.003.

27. Alam MT, Bora H, Das MK, Sharma YD. The type and mysorensis forms of the Anopheles stephensi (Diptera: Culicidae) in India exhibit identical ribosomal DNA ITS2 and domain-3 sequences. Parasitol Res. 2008;103:75-80. doi: 10.1007/s00436-008-0930-7.

28. Bhinder P, Chaudhry A, Barna B, Kaur S. Imidacloprid and Thiamethoxam Induced Mutations in Internal Transcribed Spacer 2 (ITS2) of Anopheles stephensi. Toxicol Int. 2012; 19:201-6. doi: 10.4103/0971-6580.97223

29. Munawar K, Saleh A, Afzal M, Qasim M, Khan KA, Zafar MI, et al. Molecular characterization and phylogenetic analysis of anopheline (Anophelinae: Culicidae) mosquitoes of the Oriental and Afrotropical Zoogeographic zones in Saudi Arabia. Acta Trop. 2020; 207:105494. doi: 10.1016/j.actatropica.2020.105494.

30. Livak KJ. Organization and mapping of a sequence on the Drosophila melanogaster X and Y chromosomes that is transcribed during spermatogenesis. Genetics. 1984; 107:611-34.

31. Christophers SR. The fauna of British India, including Ceylon and Burma. 1933, Vol IV., Diptera, Family Culicidae, Tribe Anophelini; London: Taylor and Francis. 371 pp. 
32. Beebe NW, Saul A. Discrimination of all members of the Anopheles punctulatus complex by polymerase chain reaction--restriction fragment length polymorphism analysis. Am J Trop Med Hyg. 1995; 53:478-81. doi: 10.4269/ajtmh.1995.53.478.

33. Litvaitis MK, Nunn G, Thomas WK, Koche TD. A molecular approach for the identification of Meiofaunal turbellarians (Platyhelminthes, Turbellaria). Marine Biol. 1994; 120, 437-42.

34. Campbell BC, Steffen-Campbell JD, Werren JH. Phylogeny of the Nasonia species complex (Hymenoptera: Pteromalidae) inferred from an internal transcribed spacer (ITS2) and 28S rDNA sequences. Insect Mol Biol. 1993; 2:225-37. doi: 10.1111/j.1365-2583.1994.tb00142.x.

35. Zhang W, Tian W, Gao Z, Wang G, Zhao H. Phylogenetic Utility of rRNA ITS2 SequenceStructure under Functional Constraint. Int J Mol Sci. 2020 3; 21:6395. doi: 10.3390/ijms21176395.

36. Bezzhonova OV, Goryacheva II. Intragenomic heterogeneity of rDNA internal transcribed spacer 2 in Anopheles messeae (Diptera: Culicidae). J Med Entomol. 2008; 45:337-41. doi: 10.1603/0022-2585(2008)45[337:ihorit]2.0.co;2.

37. Fairley TL, Kilpatrick CW, Conn JE. Intragenomic heterogeneity of internal transcribed spacer rDNA in neotropical malaria vector Anopheles aquasalis (Diptera: Culicidae). J Med Entomol. 2005; 42:795-800. doi: 10.1093/jmedent/42.5.795.

38. Li C, Wilkerson RC. Intragenomic rDNA ITS2 variation in the neotropical Anopheles (Nyssorhynchus) albitarsis complex (Diptera: Culicidae). J Hered. 2007; 98:51-9. doi: 10.1093/jhered/es1037.

39. Onyabe DY, Conn JE. Intragenomic heterogeneity of a ribosomal DNA spacer (ITS2) varies regionally in the neotropical malaria vector Anopheles nuneztovari (Diptera:Culicidae). Insect Mol Biol. 1999; 8:435-42. doi: 10.1046/j.1365-2583.1999.00134.x.

40. Whang IJ, Jung J, Park JK, Min GS, Kim W. Intragenomic length variation of the ribosomal DNA intergenic spacer in a malaria vector, Anopheles sinensis. Mol Cells. 2002; 14:158-62.

41. Polanco C, González AI, de la Fuente, Dover GA. Multigene family of ribosomal DNA in Drosophila melanogaster reveals contrasting patterns of homogenization for IGS and ITS spacer regions. A possible mechanism to resolve this paradox. Genetics. 1998; 149:243-56.

42. Ironside JE. Diversity and recombination of dispersed ribosomal DNA and protein coding genes in microsporidia. PLoS One. 2013; 8:e55878. doi: 10.1371/journal.pone.0055878

43. Goldman AS, Lichten M. The efficiency of meiotic recombination between dispersed sequences in Saccharomyces cerevisiae depends upon their chromosomal location. Genetics. 1996; 144:4355

44. Jiang X, Peery A, Hall AB, Sharma A, Chen XG, Waterhouse RM, et al., Genome analysis of a major urban malaria vector mosquito, Anopheles stephensi. Genome Biol. 2014; 15:459. doi: 10.1186/s13059-014-0459-2.

45. Dover G, Coen E. Springcleaning ribosomal DNA: a model for multigene evolution? Nature. 1981; 290:731-2. doi: 10.1038/290731a0

46. Keller I, Chintauan-Marquier IC, Veltsos P, Nichols RA. Ribosomal DNA in the grasshopper Podisma pedestris: escape from concerted evolution. Genetics. 2006; 174:863-74. doi: 10.1534/genetics.106.061341.

47. Sharma D, Lather M, Dykes CL, Dang AS, Adak T, Singh OP. Disagreement in genotyping results of drug resistance alleles of the Plasmodium falciparum dihydrofolate reductase (Pfdhfr) gene by allele-specific PCR (ASPCR) assays and Sanger sequencing. Parasitol Res. 2016; 115:323-8. doi: 10.1007/s00436-015-4750-2. 
Table 1: Number of samples subjected to direct sequencing of rDNA regions

\begin{tabular}{lccc}
\hline Population & Geographical & \multicolumn{2}{c}{ rDNA region } \\
\cline { 2 - 4 } & coordinates & ITS2 & 28S (d1-d3) \\
\hline 1. Delhi & $28.63,77.15$ & 2 & 0 \\
\hline 2. Gurugram (Haryana) & $28.43,76.97$ & 4 & 4 \\
\hline 3. Nuh (Haryana) & $28.10,76.99$ & 4 & 4 \\
\hline 4. Alwar (Rajasthan) & $27.55,76.62$ & 4 & 4 \\
\hline 5. Ranchi (Jharkhand) & $23.36,85.32$ & 9 & 9 \\
\hline 6. Raipur (Chhatishgarh) & $21.26,81.63$ & 1 & 1 \\
\hline 7. Gadchiroli (Maharashtra) & $20.18,79.99$ & 2 & 2 \\
\hline 8. Goa (UT) & $15.36,74.03$ & 4 & 4 \\
\hline 9. Bengaluru (Karnataka) & $13.01,77.61$ & 2 & 2 \\
\hline 10. Mangalore (Karnataka) & $12.92,74.85$ & 4 & 4 \\
\hline 11. Mysuru (Karnataka) & $12.31,76.64$ & 3 & 3 \\
\hline 12. Chennai (Tamil Nadu) & $13.06,80.23$ & 5 & 2 \\
\hline 13. Laboratory colony: “type form” & & 2 & 2 \\
\hline (Jodhpur, Rajasthan) & & & 46 \\
\hline & & 2 & \\
\hline
\end{tabular}


Table 2: Distribution of haplotypes in clonal DNA samples (nucleotide base position numbering based on the alignment displayed in Figure 2)

\begin{tabular}{|c|c|c|c|c|c|c|c|c|c|}
\hline \multirow[t]{4}{*}{ Haplotypes } & \multicolumn{5}{|c|}{ Base positions } & \multicolumn{4}{|c|}{ Number of clones } \\
\hline & 1 & 1 & 1 & 3 & 4 & Nuh & Gadchiroli & Bengaluru & Total \\
\hline & 7 & 8 & 8 & 8 & 0 & (northern India) & (central India) & (southern India) & \\
\hline & 2 & 2 & 3 & 3 & 1 & & & & \\
\hline Hap-1 & $\mathrm{C}$ & $\mathrm{C}$ & $\mathrm{A}$ & $\mathrm{C}$ & $\bar{G}$ & 12 & 11 & 7 & 30 \\
\hline Hap-2 & $\mathrm{T}$ & - & - & $\mathrm{C}$ & $\mathrm{G}$ & 4 & 2 & 3 & 9 \\
\hline Hap-3 & $\mathrm{T}$ & - & - & $\mathrm{C}$ & $\mathrm{A}$ & 3 & 1 & 3 & 7 \\
\hline Hap-4 & $\mathrm{C}$ & - & - & $\mathrm{T}$ & $\mathrm{G}$ & 3 & 2 & 1 & 6 \\
\hline Hap-5 & $\mathrm{C}$ & $\mathrm{C}$ & $\mathrm{A}$ & $\mathrm{T}$ & $\mathrm{G}$ & 2 & 1 & 2 & 5 \\
\hline Hap-6 & $\mathrm{C}$ & $\mathrm{C}$ & A & $\mathrm{C}$ & A & 1 & 0 & 2 & 3 \\
\hline Hap-7 & $\mathrm{C}$ & $\mathrm{C}$ & $\mathrm{A}$ & $\mathrm{T}$ & $\mathrm{A}$ & 0 & 0 & 1 & 1 \\
\hline Hap-8 & $\mathrm{T}$ & $\mathrm{C}$ & $\mathrm{A}$ & $\mathrm{T}$ & $\mathrm{G}$ & 0 & 0 & 1 & 1 \\
\hline Hap-9 & $\mathrm{C}$ & - & - & $\mathrm{C}$ & $\mathrm{A}$ & 0 & 1 & 0 & 1 \\
\hline Hap-10 & $\mathrm{C}$ & - & - & $\mathrm{C}$ & $\mathrm{G}$ & 0 & 1 & 0 & 1 \\
\hline Total & & & & & & 25 & 19 & 20 & 64 \\
\hline
\end{tabular}




\section{Ligands to Figures}

Figure 1 Geographical location of mosquito sampling sites

Figure 2 Alignment of haplotypes of complete ITS2 sequence of An. stephensi (the flanking 5.8S and 28S rDNA sequences are not shown here). The polymorphic loci have been highlighted (SNPs at three base positions, i.e., 172, 383 and 401; two bp indel at base positions 182-183). Dot represents similarity with Hap-1 sequence and dash represents gap in nucleotide sequence.

Figure 3 Snapshots of portions of ITS2 chromatogram showing polymorphic sites. Polymorphism $172 \mathrm{C}>\mathrm{T}$ and 182_183del can be seen in forward sequence (a) and 372C $>\mathrm{T}$ and $401 \mathrm{G}>\mathrm{A}$ can be seen in reverse sequence (b) chromatogram. The ambiguity (mixed bases) in sequences can be seen from the point of indel onwards (a).

\section{Supplementary information}

File S1: Annotation features of GenBank entries 

AAACCTAAACACACACACACACATGTGAGCATGGGTGAAGAGCGAGCGCGCGTCAAGTCGCACGGTTCGACCTCTAGTAT

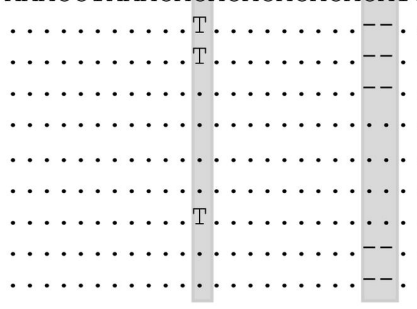

TAACACTTGCGGCCCAACGCGCTCGTATCTTTCCTCGCATCCAGTTGCAGTCGCGAGACGTGCTCACGCCGTGTGGGTGA 400

\section{GTGAGGTTAGCACGACAGGGGTGATTTATCACCGCTTCTCCCGTCGCATCATTGTGACAGTGGAGTCTGT 470}

A.

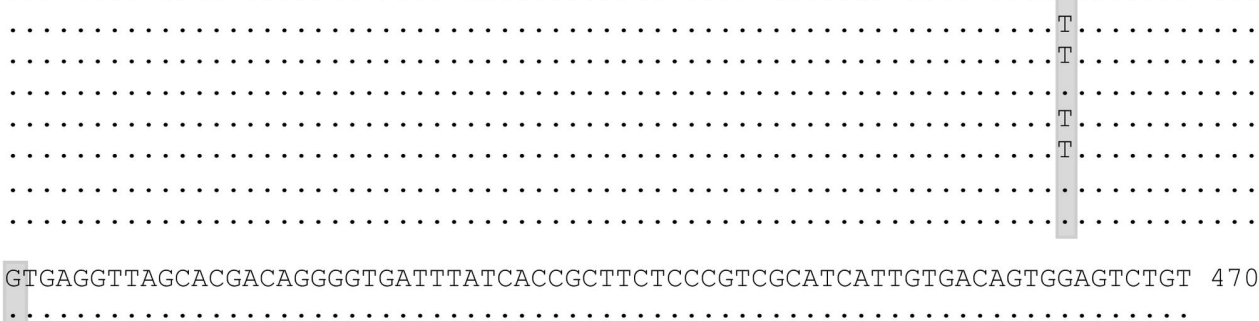



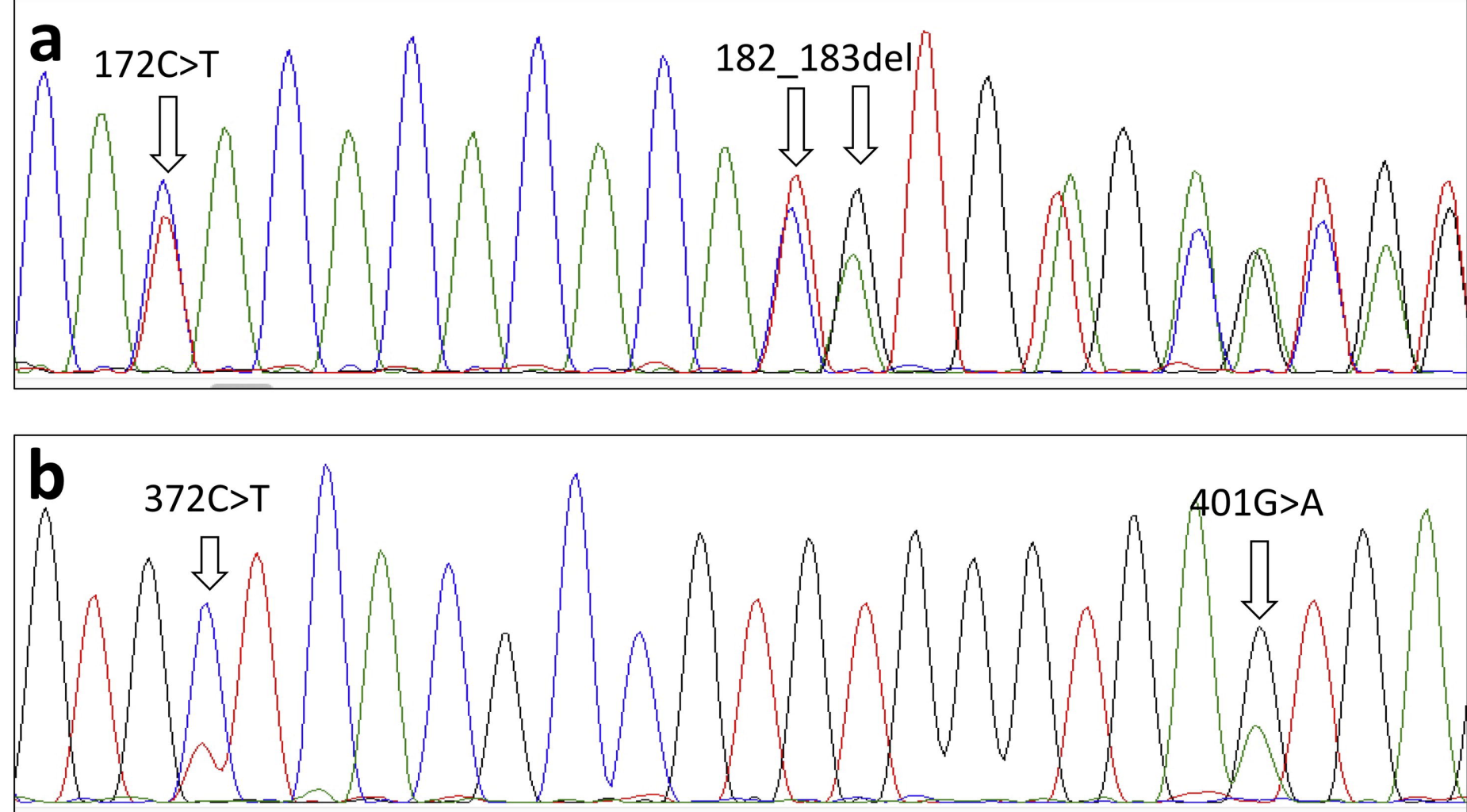